\title{
A utilização de Tecnologia Assistiva na vida cotidiana de crianças com deficiência
}

\author{
The use of assistive technology \\ in the daily activities of children with disabilities
}

Renata Cristina Bertolozzi Varela ${ }^{1}$

Fátima Corrêa Oliver ${ }^{1}$

${ }^{1}$ Departamento de Fisioterapia Fonoaudiologia e Terapia Ocupacional, Universidade de São Paulo. R. Cipotânea 51, Butantã. 05360160 São Paulo SP. renatacbv@hotmail.com

\begin{abstract}
The scope of this study is to understand the use of assistive technology in the everyday life of children with disabilities, based on the concept of everyday life as a space for expression of particularity and generality of individuals. It was developed from documentary research of medical records, application of a form, observation of daily activities of children and their families and semistructured interviews. Five children were studied, representatives in age, sex, diagnosis and use of technological resources, who were attended in primary healthcare units in São Paulo. The resources are used in homes, schools and other environments and their use is influenced by family and social relations and by the possibility of accessing products and services. It was established that the everyday activities and the use of resources are organized according to the time, space, ways in which children and, mainly, their caregivers act, showing the presence of pragmatism, economy and spontaneity typical of everyday life. The results revealed elements that can guide the practice of professionals working with assistive technology and can contribute to enable the appraisal of providing equipment in the Unified Health System. Key words Self-help devices, Daily activities, Children with disabilities, Social inclusion, Public health polices
\end{abstract}

Resumo Este estudo visa compreender a utilização por crianças com deficiência de tecnologia assistiva na vida cotidiana, considerando esta como espaço de expressão da particularidade e da genericidade dos indivíduos. Foi desenvolvido com pesquisa documental de prontuários, aplicação de formulário, observação de atividades cotidianas das crianças e suas famílias e entrevista semiestruturada. Foram estudadas cinco crianças, representativas em idade, sexo, diagnóstico e uso de tecnologia assistiva, atendidas em serviço de atenção básica em saúde do Município de São Paulo. Os recursos são empregados nos domicílios, escolas e outros ambientes e seu uso é influenciado pelas relações familiares e sociais e pela possibilidade de acesso a bens e serviços. Verificou-se que as atividades cotidianas e o uso dos recursos se organizam em função do tempo, dos espaços, dos modos de agir da criança e, principalmente, de seus cuidadores, evidenciando a presença do pragmatismo, economicismo e espontaneidade típicos da vida cotidiana. Os resultados levantaram elementos que podem orientar a prática de profissionais no trabalho com tecnologia assistiva e contribuir para as avaliações sobre a concessão de equipamentos no Sistema Único de Saúde.

Palavras-chave Equipamentos de autoajuda, Atividades cotidianas, Crianças com deficiência, Inclusão social, Políticas públicas de saúde, Terapia ocupacional 


\section{Introdução}

A aquisição de uma deficiência em qualquer etapa da vida de um indivíduo é uma condição que pode impactar seu cotidiano no que se refere às estruturas e funções do corpo, à realização de atividades e à participação social, conforme preconiza a Classificação Internacional de Funcionalidade ${ }^{1}$. Com o intuito de diminuir este impacto, o desenvolvimento tecnológico tem influenciado o campo da reabilitação e observa-se um crescente investimento na produção de recursos que passaram a compor o rol de ações terapêuticas destinadas a atender às necessidades das pessoas com deficiência que, no censo 2010, representavam cerca de $14,5 \%$ da população brasileira ${ }^{2}$.

No Brasil, estes recursos têm sido denominados de "Tecnologia Assistiva" (TA), tanto no meio acadêmico como nas organizações de pessoas com deficiência e no mercado de produtos. Esta terminologia foi oficializada pelo Comitê de Ajudas Técnicas da Subsecretaria Nacional de Promoção dos Direitos da Pessoa com Deficiência e é considerada como uma área interdisciplinar do conhecimento, que engloba produtos, recursos, metodologias, estratégias, práticas e serviços para promover a funcionalidade, relacionada à atividade e participação de pessoas com deficiência, incapacidades ou mobilidade reduzi$\mathrm{da}$, para lhes proporcionar autonomia, independência, qualidade de vida e inclusão social ${ }^{3}$.

A TA é um fator ambiental e inclui produtos e tecnologias para uso pessoal na vida diária, facilitação da mobilidade e transporte pessoal, comunicação, educação, trabalho, cultura, atividades recreativas e desportivas, prática religiosa e espiritualidade e arquitetura ${ }^{1}$. É também reconhecida como elemento chave para a promoção dos direitos das pessoas com deficiência ${ }^{3}$, garantido desde a promulgação do Decreto no 3.298 de 1999 que conceitua e lista as "ajudas técnicas" previstas para concessão ${ }^{4}$.

No âmbito dos serviços de saúde, na prática clínica e assistencial realizada com crianças com deficiência, a implementação de TA é fundamental para apoiar as diferentes etapas do seu desenvolvimento neuropsicomotor, oferecer condições para sua participação social e auxiliar as famílias nas ações de cuidado.

Takatori $^{5}$ considera a TA como recurso para ajudar essas crianças a conquistar independência e autonomia nas atividades cotidianas e Pelosi $^{6}$ destaca sua importância como apoio ao processo de inclusão escolar dos alunos com deficiência.
No entanto, uma das questões a ser discutida neste processo refere-se à possibilidade de acesso desta parcela da população aos recursos produzidos pela comunidade científica e ofertados no mercado de produtos. No Brasil, muitos recursos desenvolvidos nas universidades não são incorporados ao mercado, a variedade de produtos fabricados no país é pequena e grande parte dos dispositivos importados não dispõe de isenção tributária, elevando significativamente o custo da TA disponível no mercado.

Souza e Carneiro ${ }^{7}$, quando discutem a relação entre deficiência e pobreza, apontam para uma maior concentração de pessoas com deficiência em famílias de baixa renda, que acessam de forma restrita a bens e serviços que poderiam favorecer suas condições de sobrevivência e bem-estar. Demonstram que a presença de pessoas com deficiência interfere negativamente na renda familiar, já que suas famílias precisam assumir o ônus relacionado aos cuidados que demandam. Outra pesquisa publicada por Cavalcante e Minayo $^{8}$ apresentou as principais dificuldades referidas por famílias de crianças com deficiência, entre elas a falta de condições materiais para lhes oferecer conforto e assistência.

Diante deste cenário, é importante considerar que, para muitas famílias, o acesso à TA restringe-se aos recursos disponíveis no Sistema Único de Saúde (SUS), que constam da lista de concessão de órteses e próteses ${ }^{9}$ e com somente alguns modelos básicos de equipamentos para locomoção e de dispositivos para deficiência visual e auditiva.

Outra questão refere-se à necessidade de reformulação das práticas, pois a indicação de TA seguindo uma racionalidade puramente tecnológica, como discute Campos ${ }^{10}$, pode partir do princípio de que a tecnologia é adequada $a$ priori e não considerar os contextos singulares do usuário, o que não garante a integração dos recursos na vida cotidiana das crianças e seus familiares. Nesta perspectiva, ressalta-se a importância de se compreender que a indicação e a utilização de TA é um processo multidimensional, conforme define Castiglioni ${ }^{11}$. Para a autora, a escolha, por exemplo, de uma cadeira de rodas, deve basearse nas especificações do produto, em função das necessidades posturais e funcionais da criança, delimitando uma dimensão mecânico-instrumental. Mas, além disso, precisa levar em conta os contextos político, social, cultural e econômico, de maneira a garantir que a criança tenha acesso ao recurso, o que caracteriza uma dimensão ético-política. E também é necessário consi- 
derar as expectativas e as representações subjetivas envolvidas na relação da criança e seus familiares com este recurso, o que caracteriza uma dimensão afetivo-subjetiva de seu uso.

Com base nestas considerações, faz-se necessário o desenvolvimento de pesquisas que justifiquem a importância da TA e caracterizem o seu uso na vida cotidiana das pessoas com deficiência, para reforçar a argumentação sobre a efetivação de seus direitos e fornecer diretrizes para a estruturação de políticas públicas também no âmbito da concessão de equipamentos. Este estudo pretendeu colaborar com esta discussão elegendo a vida cotidiana como unidade de análise, a partir da concepção que a toma como instância na qual, ao mesmo tempo em que se reproduzem as relações macrossociais, produzem-se inovações, resistências à dominação, transformações significativas para o indivíduo e para a sociedade, tal como afirma Heller ${ }^{12}$. Neste sentido, esta concepção se opõe às ideias do senso comum que enfatizam somente o aspecto banal, corriqueiro, repetitivo e privado da vida cotidiana.

A vida cotidiana pode ser analisada considerando as atividades que nela se instituem, como por exemplo, as Atividades da Vida Diária (AVD), tão enfatizadas no ambiente idealizado de reabilitação, e definidas pela American Occupational Therapy Association ${ }^{13}$ como uma área do desempenho ocupacional, composta pelas atividades de autocuidado, como banho, alimentação, vestuário, entre outras. Mas além destas atividades, a análise também precisa incluir as complexas relações que envolvem o meio, a pessoa e sua participação, com informações que podem subsidiar abordagens inovadoras, como destacou $\mathrm{Law}^{14}$. Esta autora lembra que a participação nas atividades cotidianas é uma parte vital do desenvolvimento humano, e que através dela adquirimos competências, nos conectamos com outros e com nossas comunidades e atribuímos propósitos e significados à vida.

Neste estudo considerou-se que a utilização da TA pela criança pode apoiar sua participação nas dimensões que correspondem aos componentes orgânicos da vida cotidiana, que envolvem diferentes atividades, heterogêneas em relação ao conteúdo, significação e importância, e que se organizam no tempo e nos espaços segundo uma hierarquia determinada pelo contexto social, conforme discutiu Heller ${ }^{12}$.

Contudo, a TA deve se integrar de modo a tomar parte nas relações entre pensamento e ação, pois para Heller ${ }^{12}$, a cotidianidade não seria possível sem um modo específico de intera- ção entre estes elementos, do qual a espontaneidade, o pragmatismo e o economicismo são exemplos. A espontaneidade é a tendência de que as ações que compõem a vida cotidiana sejam realizadas de modo dissociado da reflexão sobre seu conteúdo de verdade material ou formal; o pragmatismo pode ser demonstrado no fato de que a ação cotidiana não se eleva ao plano da teoria e que o pensamento tem como foco a concretização da atividade; o economicismo refere-se ao fato de que, na vida cotidiana, toda categoria de ação e pensamento só é mantida enquanto é imprescindível para a continuação da atividade ${ }^{12}$. Essas características, ao lado de outras discutidas pela autora, são estruturantes da vida cotidiana e evidenciam uma unidade imediata entre o pensamento e a ação, sem a qual não haveria tempo suficiente para que a vida cotidiana fluísse em sua regularidade.

Tendo em vista, ainda, que a vida cotidiana reflete o homem enquanto ente individual $\mathrm{e}$ humano-genérico - uma singularidade e uma parte orgânica da humanidade, simultaneamente - considerou-se importante reconhecer que, embora a criança compartilhe uma cotidianidade forjada e orientada socialmente, sua motivação e necessidades são particulares, referidas ao "eu"12. Cada criança, portanto, e também seus familiares, experimentam barreiras e possibilidades singulares de ação, ligadas às objetivações inerentes à vida cotidiana e às subjetivações relacionadas à existência de uma deficiência, de modo que a utilização da TA pode ser vivenciada como fator que amplia ou limita sua participação nas atividades.

A partir deste referencial, o presente estudo objetivou também conhecer a vida cotidiana de crianças com deficiência, constituída pelas diferentes atividades que realizam, em função do tempo, dos espaços em que circulam e das relações que estabelecem, investigando como, onde e por que a TA é, ou não, utilizada e levantando elementos que possam contribuir para a construção de práticas assistenciais.

\section{Método}

Este estudo, realizado entre 2008 e 2010, foi fundamentado na metodologia qualitativa, investigando os sentidos próprios que as crianças com deficiência e seus familiares atribuem ao uso de TA e interpretando os fenômenos observados na relação que estabelecem com os recursos utilizados nas atividades cotidianas ${ }^{15}$. 
Foi sediado em uma Unidade Básica de Saúde (UBS) da Secretaria Municipal de Saúde, localizada na região oeste da cidade de São Paulo, que atende cerca de dezenove mil pessoas, conta com seis equipes de Estratégia de Saúde da Família e subsidia atividades de ensino para profissionais de saúde.

Inicialmente, foi realizado estudo dos prontuários de todas as crianças com deficiência cadastradas na UBS, na faixa etária de 0 a 14 anos, registrando dados gerais de identificação e de sua condição de saúde. Foram localizadas 22 crianças, que foram visitadas para aplicação de um formulário de caracterização, respondido pelos cuidadores, que levantou dados destes, breve histórico da deficiência, composição e renda familiar, acompanhamentos em reabilitação e escolas frequentados e atividades cotidianas realizadas pela criança. Os responsáveis assinaram Termo de Consentimento Livre e Esclarecido e também foi solicitado o consentimento verbal das crianças. O projeto foi aprovado pelo Comitê de Ética em Pesquisa da Secretaria Municipal da Saúde e da universidade onde se desenvolveu o programa de pós-graduação.

Este estudo preliminar permitiu caracterizar as crianças cadastradas no serviço, favoreceu a constituição de vínculos da pesquisadora com o campo de estudos, com as crianças, seus familiares e a equipe de saúde. A partir da análise descritiva destes dados, foram escolhidas cinco crianças que utilizassem algum tipo de recurso e representassem o grupo quanto à idade, gênero e tipo de deficiência e, para explorar a forma singular com que utilizam a TA em sua vida cotidiana realizou-se observação de atividades e entrevista.

A observação seguiu um roteiro com questões sobre o ambiente (organização do espaço, posição da criança e da pesquisadora), as atividades (quais, como e com quem a criança as realizava; tempo despendido; se recebeu ajuda e por que), a utilização de TA (quais os recursos existentes; em quais situações foram utilizados ou que poderiam ser, mas não foram e por que; como as pessoas se relacionavam com o recurso) e as relações interpessoais estabelecidas (interações da criança e de outros atores).

Cada criança foi acompanhada durante dois dias não consecutivos, mas próximos, para produzir um efeito de continuidade, por um período de no mínimo seis e no máximo nove horas seguidas. A observação contemplou atividades que as crianças realizavam em casa, como as relacionadas ao autocuidado, ao uso do tempo livre, ao relacionamento com outras pessoas. Também foram incluídas as atividades realizadas em outros ambientes, como a escola, instituições de reabilitação e projetos assistenciais na comunidade.

Foram necessárias várias idas ao campo antes da observação propriamente dita para favorecer o fluir da rede de relações ${ }^{16}$. A pesquisadora procurou o entrosamento com a criança e seus familiares, interagindo nas brincadeiras e conversas, compreendendo a importância de se investir nesta relação e ser aceita na convivência para favorecer a inserção no campo de estudo ${ }^{17}$. Esta interação também compôs o objeto de investigação, pois os registros no diário de campo incluíram a cena social, os acontecimentos e as interpretações que envolveram a atuação da pesquisadora junto às crianças e suas famílias ${ }^{18}$

Após a conclusão das observações, foram realizadas as entrevistas com os cuidadores. A relação anteriormente estabelecida com os entrevistados favoreceu uma empatia benéfica para a reflexão pretendida ${ }^{19}$ e as informações apreendidas nas observações serviram de suporte para a condução da entrevista.

A entrevista foi guiada por um roteiro com questões referenciadas na percepção dos cuidadores sobre as atividades cotidianas (como é um dia típico da criança, como esta participa nas atividades da família, quem define quais atividades ela deve realizar e por que, se ela tem possibilidade de fazer o que gosta), a deficiência (quais as dificuldades vivenciadas com a criança no dia a dia e o auxílio oferecido para as atividades) e a TA (quais recursos existentes, quem os indicou, em que situações e com que frequência são utilizados, se receberam algum tipo de orientação para o uso).

Os apontamentos do diário de campo foram usados para reconstruir a sequência dos acontecimentos observados. A leitura deste material, somada ao conteúdo transcrito das entrevistas, foi sistematicamente realizada, procurando levantar temas que se referiam às características da vida cotidiana das crianças e sua relação com a utilização de TA.

O primeiro tema se relaciona com a fluência e a sucessão de experiências da vida cotidiana, que envolvem elementos como o tempo, os espaços e as relações interpessoais, a hierarquia e a heterogeneidade das atividades ${ }^{12} \mathrm{e}$ a ruptura provocada nesta fluência pelo nascimento de uma criança com deficiência e a necessidade de adaptar os modos de agir ao longo da vida.

A partir da compreensão de que os recursos de TA são elementos mediadores da experiência da criança e de sua família na vida cotidiana, o 
segundo tema refere-se à relação da TA com as atividades que envolvem habitar, comer, conversar, passear e trabalhar que, a exemplo das ideias debatidas por Kujawski ${ }^{20}$, são categorias que podem fundamentar a compreensão da vida cotidiana na tradição histórica.

Para a apresentação dos resultados e análises, optou-se por usar a forma narrativa, sem transcrições literais das falas dos participantes do estudo.

\section{Resultados e discussão}

\section{Apresentação das crianças e das atividades observadas}

Rafael, Natasha, Alberto, Davi, Jaciara e seus familiares foram os participantes do estudo, com os quais a pesquisadora compartilhou experiências significativas como brincar, ajudar as crianças, cooperar com os cuidadores, contar histórias e conversar, ensinar e aprender, conhecer e ser conhecido. O Quadro 1 apresenta os participantes, com nomes fictícios para preservar suas iden- tidades, a indicação da idade e o diagnóstico das crianças.

A variabilidade referente à composição do núcleo de moradores e às características das moradias destas famílias foi fator que incrementou esta experiência e está representada no Quadro 2 .

A variabilidade também estava presente nas atividades observadas e na TA utilizada, conforme ilustra o Quadro 3.

\section{A fluência e a sucessão de experiências na vida cotidiana das crianças}

O primeiro subtema levantado refere-se à ruptura provocada na fluência da vida cotidiana das crianças e seus familiares em decorrência da deficiência e a consequente necessidade de reorganizarem suas atividades. A complexidade da doença de Natasha impunha a necessidade de que ela, ao nascer, fosse transportada sobre um travesseiro e viesse para São Paulo em busca de tratamento e melhor condição de vida em companhia de sua avó, pois sua mãe tinha dificuldades subjetivas e econômicas para assumir este

Quadro 1. Crianças que participaram do estudo, segundo idade, diagnóstico e cuidadores principais.

\begin{tabular}{|l|c|l|l|}
\hline \multicolumn{1}{|c|}{ Criança } & Idade (em anos) & \multicolumn{1}{c|}{ Diagnóstico } & \multicolumn{1}{c|}{ Cuidadores principais } \\
\hline Rafael & 5 & Paralisia Cerebral tipo diparesia & Ana (avó paterna) \\
\hline Natasha & 6 & Osteogênese Imperfeita & Vilma (avó materna) \\
\hline Alberto & 6 & Paralisia Cerebral tipo atetoide & Marta (avó materna) \\
\hline Davi & 11 & Distrofia Muscular tipo Duchenne & Ivete (mãe) \\
\hline Jaciara & 14 & Paralisia Cerebral tipo diparesia & Silvia (mãe) \\
\hline
\end{tabular}

Quadro 2. Composição do núcleo de moradores e características da moradia das crianças que participaram do estudo.

\begin{tabular}{|l|l|l|}
\hline Criança & \multicolumn{1}{|c|}{ Núcleo de moradores } & \multicolumn{1}{c|}{ Características da moradia } \\
\hline Rafael & Avó, pai e sete familiares & $\begin{array}{l}\text { Apartamento com } 5 \text { cômodos, localizado no quarto andar de } \\
\text { um prédio sem elevador }\end{array}$ \\
\hline Natasha & $\begin{array}{l}\text { Avó, duas irmãs e quatro } \\
\text { pensionistas }\end{array}$ & $\begin{array}{l}\text { Casa de } 4 \text { cômodos, situada no segundo andar de uma construção } \\
\text { de dois andares }\end{array}$ \\
\hline Alberto & Avó, mãe, pai e tio & Sobrado com 8 cômodos \\
\hline Davi & Mãe & Casa térrea com 3 cômodos \\
\hline Jaciara & Mãe, pai e um irmão & Casa térrea com 6 cômodos \\
\hline
\end{tabular}




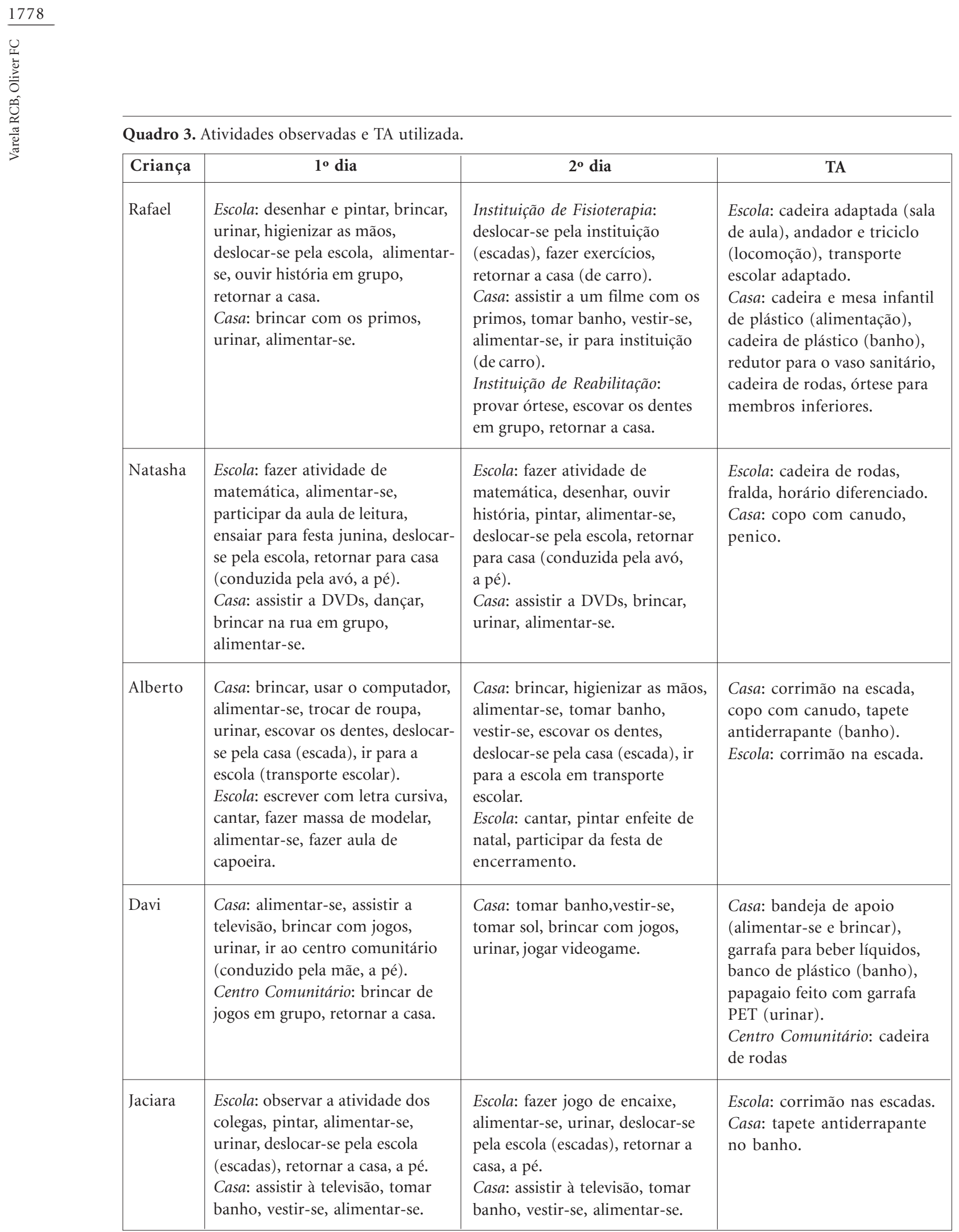

cuidado, assim como também aconteceu com a mãe de Rafael. Atualmente, Natasha conquistou mais autonomia, e outras modificações são necessárias, como fazer um horário diferenciado na escola e usar fraldas para não ter que ser levada ao banheiro, para não se fraturar. Para Sá e Rabinovich $^{21}$, o nascimento de uma criança com deficiência altera significativamente o curso da 
vida imaginada pela sua família e estabelece a necessidade de uma readaptação das expectativas e papéis desempenhados para oferecer suporte à criança.

No caso de Alberto, esta ruptura foi vivida anos após o seu nascimento e mudanças foram impostas em função da progressividade de sua doença, pois Ivete, angustiada com a piora do quadro e com a falta de opções de tratamento, saiu de sua cidade natal, o que representou uma significativa perda de sua rede de apoio social. Dúvidas, dificuldades e incertezas são sentimentos constantemente manifestados pelos cuidadores, que empenham esforços contínuos para aprender e obter melhores esclarecimentos sobre como agir na vida cotidiana, com a convicção de estarem fazendo o melhor possível para suas crianças, como constataram Falkenbach et al. ${ }^{22}$.

Após assumir os cuidados de Rafael, Ana negociou com o patrão duas folgas semanais para acompanhá-lo às terapias e aos tratamentos médicos. Martinez e Alves ${ }^{23}$ verificaram que nas famílias em que há uma criança com deficiência, são comuns as mudanças na vida cotidiana em relação ao trabalho dos cuidadores, às atividades domésticas e de lazer, às atividades realizadas entre os pais e a criança, à filosofia de vida e à dinâmica do casal.

A ampliação do tempo para as atividades cotidianas em função de suas necessidades particulares é outro subtema referido pelos participantes. Silvia já foi orientada pelas terapeutas ocupacionais a permitir que Jaciara troque de roupa sozinha, mas não consegue fazer isso nos dias em que ela vai às terapias, pois a filha faz a tarefa em ritmo lento. O tempo disponível não é suficiente, pois precisa se moldar às exigências sociais, de forma a limitar a experiência da criança.

O impacto das características do espaço físico na promoção da independência da criança também foi levantado. Natasha se desloca sentada no chão e precisa que alguém a carregue nas escadas de acesso a sua casa, para ir à escola ou para brincar na rua. O espaço limitado do domicílio de Rafael é um dos fatores que dificulta a utilização de sua cadeira de rodas.

A modificação dos modos de agir na vida cotidiana também é significativa, em função das necessidades da criança, dos recursos disponíveis no ambiente e da criatividade e repertório cultural dos familiares. Em casa, Natasha come apoiando seu prato no chão e usa o penico para fazer suas necessidades fisiológicas na sala, para evitar que ela sofra quedas dos mobiliários destinados a estas atividades. Esta maneira particular esco- lhida pode ser compreendida como algo inadequado do ponto de vista das regras sociais, mas é importante considerar a diversidade cultural inerente aos modos de agir, que nem sempre podem ser normatizados por orientação técnica de como adaptá-los.

É na dimensão dos tempos, dos espaços, dos modos de agir, que a ideia da heterogeneidade das atividades cotidianas ${ }^{12}$, definida socialmente, se particulariza para essas crianças. As atividades cotidianas de Rafael, Alberto e Natasha são diversificadas e semelhantes às das crianças de suas faixas etárias: vão à escola, brincam e fazem as rotinas de autocuidado. O que os diferencia é a necessidade de irem às terapias e aos tratamentos médicos, de forma que a reabilitação é mais um elemento do repertório de suas atividades.

Davi aguarda vaga na escola e tem contato com poucas crianças de sua idade. Jaciara, apesar de frequentá-la, quase não se relaciona com os colegas e, em casa, passa a maior parte do tempo assistindo à televisão. Ambos vivem restrições no convívio social, e isso é significativo na faixa etária e no contexto em que se encontram, pois as crianças que moram nesta região costumam ocupar o tempo livre brincando na rua, onde estabelecem seus círculos de amizades, como apontaram Aoki et al. ${ }^{24}$.

É preciso considerar, ainda, que há uma relação de dependência entre a organização da heterogeneidade e a hierarquia das atividades cotidianas $^{12}$ das crianças e dos seus cuidadores. Rafael solicita a presença da avó e Davi de sua mãe, constantemente: pedem ajuda para as atividades e elas interrompem suas tarefas para atendê-los. Ana conta com o apoio dos familiares que moram com ela e que ficam com Rafael nos dias em que trabalha. Ivete não sai de casa sem levar Davi, pois não tem com quem compartilhar o seu cuidado, já que está distante da família e dos amigos e precisa planejar suas atividades em função das necessidades do filho. Alberto quer companhia em tempo integral e alguém tem que estar disponível para ele. Silvia faz várias atividades ao mesmo tempo, como cozinhar e pentear os cabelos de Jaciara. Vilma tem outra neta que ajuda a cuidar de Natasha e recebe ajuda de vizinhos e parentes. Esta dependência é mais intensa nas situações em que os cuidadores têm uma rede de apoio social restrita, o que é frequente entre as mães de crianças com deficiência, que não têm as mesmas oportunidades de tempo e disposição para se dedicarem às suas relações e atividades sociais, conforme também concluíram Matsukura e Sime ${ }^{25}$. 
Sobre o uso da TA

na vida cotidiana das crianças

É na dimensão do habitar que os hábitos fundamentais se constituem ${ }^{20}$ e as $\mathrm{AVD}^{13}$ acontecem. Alberto utiliza um tapete antiderrapante para não escorregar durante o banho, Rafael, uma cadeira de plástico, Davi, um banco do mesmo material, o que lhes proporciona maior independência para manterem a postura nessa atividade. Jaciara também faz uso de tapete antiderrapante, no entanto, sua mãe não se sente segura em deixá-la sozinha e acredita que uma barra de apoio poderia lhe oferecer maior suporte, mas ainda não a adquiriu, pois necessita de orientação sobre onde encontrá-la no mercado de produtos. Além disso, não aceita colocar Jaciara sentada em uma cadeira durante o banho, conforme orientação feita pelos profissionais da UBS, pois tem receio que a filha perca as habilidades conquistadas, como ficar em pé e andar. Henderson et al. ${ }^{26}$ também verificaram que é comum as famílias resistirem ao uso de equipamentos que consideram impedir o desenvolvimento e o treino de habilidades que caracterizam os paradigmas tradicionais da reabilitação, mesmo que isso gere maior gasto energético e limite a participação das crianças nas atividades.

Para a realização de algumas necessidades fisiológicas (urinar), Natasha usa um penico e Davi, uma garrafa pet em substituição a um papagaio hospitalar, que Ivete implementou por considerá-lo mais higiênico. Nestes casos observa-se uma tendência de uso de utensílios que possam ser levados até a criança, o que pode ser reflexo das características do ambiente, da dificuldade em manterem as posturas requeridas para a atividade ou da necessidade de diminuir a sobrecarga dos cuidadores que, habitualmente, carregam as crianças no colo nos deslocamentos dentro do domicílio.

Na dimensão do comer $^{20}$, observou-se a importância dos serviços apoiarem soluções que auxiliem as famílias a garantir recursos básicos para a sobrevivência, tendo em vista que, em algumas casas visitadas, o acesso à alimentação só foi garantido por programas sociais. Em casa, Alberto utiliza um copo com tampa e canudo por orientação de sua fonoaudióloga; na escola, como este copo não está disponível, usa outro igual ao dos colegas, mas a professora, para facilitar seu desempenho, lhe serve uma quantidade menor de líquido. Em casa, Rafael tem uma cadeira adaptada, indicada pela terapeuta ocupacional da UBS para ser utilizada durante a alimentação, mas na escola usa uma cadeira igual à dos colegas dividindo a mesa com o grupo. Há um empenho das famílias em seguir as orientações terapêuticas, as quais não se estendem aos outros ambientes frequentados pela criança, como a escola; por outro lado, a falta do recurso adaptado não é impedimento para a atividade ser realizada.

Na dimensão do passear $^{20}$, a utilização de TA merece destaque pelo fato de, com exceção de Alberto, as demais crianças apresentarem dificuldades para a locomoção. Rafael tem prognóstico de deambulação com uso de andador e há um grande investimento na esfera terapêutica para que ele desenvolva essa habilidade. Profissionais da reabilitação indicaram órteses (goteiras e talas de lona) para alongamento e posicionamento de membros inferiores, cadeira de plástico para adequação da postura sentada em casa, cadeira de rodas para locomoção fora do domicílio, triciclo e andador para deslocamento na escola. A cadeira de rodas e a goteira foram adquiridas com recursos do SUS; o andador foi doado por outro usuário da UBS; os demais equipamentos foram adquiridos com recursos da família.

O deslocamento na escola é realizado trocando passos com o apoio de adultos e a utilização dos recursos de TA não foi observada. Em casa, Rafael permanece a maior parte do tempo no chão e se desloca ajoelhado, postura contraindicada pelos terapeutas. Ele resiste em usar as órteses e a cadeira de plástico e sua família não tem recursos financeiros para adquirir outro andador para ser utilizado em sua casa. Ele prefere se deslocar no chão ou em sua cadeira de rodas, que quase nunca é usada em função da dificuldade de transportá-la pelas escadas do prédio onde mora e da conotação subjetiva que seu uso adquire ao ser relacionado à frustração do desejo explicitado por sua avó de vê-lo andando e jogando futebol. Portanto, para os deslocamentos fora do domicílio, geralmente é transportado no colo. Estes fatos colocam em evidência a complexidade e multidimensionalidade envolvida na utilização de $\mathrm{TA}^{11}$.

Outra questão observada refere-se à falta de recursos de acessibilidade nos ambientes públicos, bem como de transporte adaptado, o que dificulta a participação em atividades de lazer, reabilitação e tratamentos médicos. Para levar Natasha ao tratamento que realiza em hospital, Vilma depende da disponibilidade de recursos financeiros para custear transporte particular, pois a falta de adaptações no transporte público lhe desencoraja a utilizá-lo. Ivete conduz a cadeira de rodas de Davi por trajetos mais longos na 
comunidade, para evitar ruas com buracos e acúmulo de lixo. Estes dados apontam para a urgência de investimento em políticas de planejamento urbano e ambiental no campo da acessibilidade, assim como preconizam Cavalvanti et al. ${ }^{27}$ Além disso, inferem a necessidade de se considerar o desgaste dos equipamentos na política de concessão.

Na dimensão do trabalhar ${ }^{20}$, por se tratar de estudo com crianças, foi utilizada a atividade de estudar, compreendendo que a escola é um dos primeiros grupos sociais com os quais a criança se relaciona para além da família.

Rafael possui uma cadeira adaptada para usar em sala de aula, mas não é posicionado adequadamente, demonstrando a necessidade de que as pessoas envolvidas nesse processo, como a professora, sejam orientadas sobre como proceder. Natasha recebe apoio de uma estagiária de terapia ocupacional em sala de aula, que favorece sua atenção e participação nas atividades. Também vivencia uma rotina escolar adaptada, que repercute sobre seu aproveitamento escolar, pois não retorna à sala de aula após o almoço, já que depende da disponibilidade de algum funcionário para lhe conduzir pelas escadas. Nestas situações, evidencia-se a importância da capacitação de recursos humanos para se somar à TA nos diferentes contextos.

Quanto a Alberto, o fato de seus pais não aceitarem que utilize recursos diferentes dos das crianças de sua idade lhe acarreta uma sobrecarga física e interfere no tempo das atividades de todo o grupo na escola, pois apesar das dificuldades de coordenação motora, é incentivado a escrever somente com letra cursiva, e os colegas precisam aguardar que ele conclua sua tarefa. Jaciara permanece a maior parte do tempo na escola somente observando as atividades dos colegas, em função da falta de materiais e atividades adaptados, e do descrédito da professora em relação às suas capacidades.

As observações revelam questões que são amplamente discutidas no âmbito da inclusão escolar das crianças com deficiência, como a falta de recursos e profissionais qualificados e a necessidade de parcerias entre os profissionais da Saúde e os da Educação, como discute Pelosi ${ }^{6}$. Para Rocha et al. ${ }^{28}$, a implementação de TA na escola pode ser uma importante estratégia de superação das dificuldades explícitas, como a eliminação de barreiras arquitetônicas, a capacitação dos educadores e o acesso aos equipamentos, ao mobiliário e ao material pedagógico adaptado; mas precisa se somar à compreensão e à ação diante das dificuldades implícitas relacionadas aos sentidos da deficiência que permeiam o imaginário social dos profissionais da escola e dos familiares.

Na dimensão do conversar ${ }^{20}$, embora todas as crianças deste estudo disponham da linguagem oral e não utilizem TA para comunicação, a preservação dessa habilidade não assegura possibilidades de relação com outros interlocutores, como no caso de Jaciara, que permanece, tanto na escola como em casa, sem conversar com pessoas de sua idade.

Analisando o uso de TA nestas cinco dimensões, observa-se que a maior parte dos recursos especializados utilizados pelas crianças estava relacionada ao passear e foi adquirida com subsídios públicos. Nas demais dimensões, prevalecem as adaptações adquiridas com recursos próprios e implementadas a partir de orientações terapêuticas, ou aquelas confeccionadas pelos familiares, feitas de acordo com os diferentes modos de agir, com instrumentos presentes no ambiente. Para Almeida ${ }^{29}$, essas soluções individualizadas e adaptadas conforme situações contextuais da vida representam a relativa escolha efetivada pelos indivíduos e, portanto, podem servir de parâmetros para o processo de indicação de TA no âmbito da assistência em saúde.

Muitas situações conhecidas a partir da entrevista com os cuidadores evidenciaram a influência da espontaneidade, do pragmatismo e do economicismo típicos da vida cotidiana ${ }^{12}$ na utilização da TA. No fluxo do tempo, dos espaços, dos modos de agir, carregar a criança no colo ou permitir que ela se desloque no chão, compõe uma unidade mais imediata entre o pensamento e a ação. Neste sentido, o uso da TA, que requer o conhecimento teórico sobre os benefícios de um determinado equipamento, como a cadeira de rodas, que proporciona posturas mais adequadas à criança e diminui a sobrecarga física dos cuidadores, pode tornar a atividade mais complexa, quebrando a regularidade da fluência da vida cotidiana. A efetivação do uso de TA em um determinado contexto de vida parece estar muito mais relacionada a esses elementos do que à sua disponibilidade na realidade das famílias, $\mathrm{o}$ que define mais um importante parâmetro para o processo de indicação de TA.

A presença dos recursos, mesmo aqueles especializados que foram adquiridos por meio do SUS, não garante sua utilização na vida cotidiana e, em contrapartida, a dificuldade de acesso a eles é fator que limita a participação em algumas atividades. A utilização do recurso não representa 
necessariamente autonomia e independência e se efetiva na relação da criança com outras pessoas; no entanto, essas crianças também recebem auxílio em muitas atividades, para as quais não têm acesso a recursos de TA. As características de um equipamento nem sempre atendem a todas as necessidades de seu usuário e a relação da criança com o recurso é dinâmica, muda em função do seu desenvolvimento e do ambiente.

Em conformidade com as informações apresentadas na revisão bibliográfica realizada por Copley e Ziviani ${ }^{30}$, sobre as barreiras para o uso de TA por crianças com deficiência, os dados deste estudo apontam para a necessidade de ampliar e diversificar os recursos de TA e modelos de equipamentos oferecidos pelo SUS, de forma a contemplar todos os domínios da vida cotidiana de seus usuários.

Outro fator refere-se à importância de incluir no processo de indicação de TA avaliações periódicas do recurso e das necessidades do usuário. Por fim, a realização de estudos de eficácia deste processo, incluindo critérios como satisfação do usuário e frequência de abandono de recursos também é fundamental para o direcionamento das políticas de concessão.

\section{Considerações finais}

A TA pode oferecer à criança oportunidades de amadurecimento, convívio, introdução na cultura, participação e inclusão social. No entanto, não garante a facilitação da vida cotidiana, mas adquire significado e utilidade distintos em ambien- tes diferentes e é desejada ou rejeitada segundo a história de vida de seus usuários, conforme indicam Rocha e Castiglioni ${ }^{31}$. Ao incorporar o conceito de vida cotidiana em sua prática assistencial, o profissional deve estabelecer uma parceria com as crianças e suas famílias, que institua proposições dialogadas e que considere tanto os modos de agir fundamentados na cultura e na história de vida, como nas possibilidades criativas, inovadoras e transformadoras destes indivíduos.

Esta perspectiva de trabalho valoriza uma racionalidade da práxis ${ }^{10}$, na medida em que o profissional se respalda em teorias e conhecimento sobre as tecnologias, mas também deve considerar que a autonomia da criança e de sua família é um dos objetivos de sua atuação, de maneira a incluir seu sistema de valores nas reflexões e tomada de decisões.

Os dados analisados neste estudo evidenciaram que, no processo de implementação de TA, é importante fundamentar-se nos componentes de estrutura e função do corpo, na atividade e na participação, considerando também fatores como custo, acessibilidade e aceitação do usuário e de seus familiares. Há também necessidade de se investir na formação de profissionais, na proposição de critérios de avaliação, no planejamento dos serviços, nas discussões sobre financiamento e no aprimoramento de produtos.

Acredita-se que este estudo levantou elementos que podem auxiliar na discussão sobre as práticas assistenciais e a política de concessão de TA no âmbito do SUS, bem como subsidiar outras pesquisas que possam aprofundar o tema em questão. 


\section{Colaboradores}

RCB Varela foi responsável pelo trabalho de campo, análise dos resultados e redação do texto. FC Oliver trabalhou na orientação metodológica e teórica, na redação e na revisão final do texto.

\section{Agradecimentos}

A Prof.Dra.Marta Almeida de Carvalho, do curso de Terapia Ocupacional da FMUSP, pela leitura atenta e sugestões ao texto. Ao Conselho Nacional de Desenvolvimento Científico e Tecnológico, pelo apoio financeiro.

\section{Referências}

1. Organização Mundial de Saúde (OMS). Classificação internacional de funcionalidade, incapacidade e saúde. São Paulo: Edusp; 2003.

2. Instituto Brasileiro de Geografia e Estatística (IBGE). Censo demográfico 2000. 2000 [acessado 2010 jun 23]. Disponível em: http://www.ibge.gov.br/home/ estatistica/populacao/censo2000.

3. Brasil. Subsecretaria Nacional de Promoção dos Direitos da Pessoa com Deficiência. Comitê de Ajudas Técnicas. Tecnologia Assistiva. Brasília: CORDE; 2009.

4. Brasil. Decreto $\mathrm{n}^{\circ} 3.298$, de 20 de dezembro de 1999. Dispõe sobre a Política Nacional para a Integração da Pessoa Portadora de Deficiência. Diário Oficial da União 1999, 21 dez.

5. Takatori, M. O brincar no cotidiano da criança com deficiência física: reflexões sobre a clínica da Terapia Ocupacional. São Paulo: Atheneu; 2003.

6. Pelosi MB. Inclusão e tecnologia assistiva [tese]. Rio de Janeiro (RJ): Faculdade de Educação; 2008.

7. Souza JM, Carneiro R. Universalismo e focalização na política de atenção à pessoa com deficiência. Saúde Soc 2007;16(3):69-84.

8. Cavalcante FG, Minayo MCS. Representações sociais sobre direitos e violência na área da deficiência. Cien Saude Colet 2009; 14(1):57-66.

9. Brasil. Portaria ${ }^{\circ} 116$, de 9 setembro de 1993. Inclui no Sistema de Informações Ambulatoriais do Sistema Único de Saúde a concessão dos equipamentos de órteses, próteses e bolsas de colostomia. Diário Oficial da União 1993; 15 set.

10. Campos GWS. A mediação entre conhecimento e práticas sociais: a racionalidade da tecnologia leve, da práxis e da arte. Cien Saude Colet 2011; 16(7):30333040 .

11. Castiglioni MC. Entre o exílio e a libertação: uma análise psicossocial da Tecnologia Assistiva [tese]. Campinas (SP): Faculdade de Psicologia; 2003.

12. Heller A. O Cotidiano e a História. São Paulo: Paz e Terra; 2000.

13. American Occupational Therapy Association. Occupational Therapy Practice Framework: Domain \& Process. Am Journ of Occ Ther 2008; 62(6):625-683.

14. Law M. Participation in the occupations of everyday life. Distinguished Scholar Lecture. Am Journ of Occ Ther 2002; 56(6):640-649.

15. Pope C, Mays N. Pesquisa qualitativa na atenção à saúde. 2a Edição. Porto Alegre: ArtMed; 2005.

16. Minayo MCS. O desafio do conhecimento: pesquisa qualitativa em saúde. 11 a Edição. São Paulo: Hucitec; 2008.

17. Neto OC. O trabalho de campo como descoberta e criação. In: Minayo MCS, organizador. Pesquisa Social - Teoria, Método e Criatividade. Petrópolis: Vozes; 2002. p.51-66.

18. May T. Pesquisa Social: questões, métodos e processos. 3a Edição. Porto Alegre: ArtMed; 2004.

19. Alberti V. Manual da História Oral. $3^{a}$ Edição. Rio de Janeiro: FGV; 2005.

20. Kujawski GM. A crise do século XX. São Paulo: Ática; 1988. 
21. Sá SMP, Rabinovich EP. Compreendendo a família da criança com deficiência física. Rev Bras Crescimento Desenvolv Hum 2006; 16(1):68-84.

22. Falkenbach AP, Drexsler G, Werler V. A relação mãe/criança com deficiência: sentimentos e experiências. Cien Saude Colet 2008; 13(Supl.2):2065-2073.

23. Martinez CMS, Alves ZMMB. Famílias que têm uma criança com atraso no desenvolvimento: algumas implicações. Rev Bras Educ Esp 1995; 3(II):113-120.

24. Aoki M, Oliver FC, Nicolau SM. Pelo direito de brincar: conhecendo a infância e potencializando a ação da Terapia Ocupacional. Rev Ter Ocup Univ São Paulo 2006; 17(2):57-63.

25. Matsukura TS, Sime MM. Demandas e expectativas de famílias de crianças com necessidades especiais: de situações do cotidiano aos técnicos envolvidos no tratamento. Temas Desenvolv 2008; 16(94): 214-221.

26. Henderson S, Skelton H, Rosenbaum P. Assistive devices for children with functional impairments: impact on child and caregiver function. Dev Med Child Neurol 2008; 50(2):89-98.

27. Cavalcanti A, Galvão C, Miranda SGS. Terapia Ocupacional e Tecnologia Assistiva: Mobilidade. In: Cavalcanti A, Galvão C, organizadores. Terapia Ocupacional: Fundamentação \& Prática. Rio de Janeiro: Guanabara Koogan; 2007. p. 427-434.

28. Rocha EF, Luiz A, Zulian MAR. Reflexões sobre as possíveis contribuições da Terapia Ocupacional nos processos de inclusão escolar. Rev Ter Ocup Univ São Paulo 2003; 14(2):72-78.

29. Almeida MC. Saúde e Reabilitação de Pessoas com Deficiência: Políticas e Modelos Assistenciais [tese]. Campinas: Faculdade de Saúde Pública; 2000.

30. Copley J, Ziviani J. Barriers to the use of assistive technology for children with multiple disabilities. Occup Ther Intern 2004; 11(4):229-243.

31. Rocha EF, Castiglioni MC. Reflexões sobre recursos. Rev Ter Ocup Univ São Paulo 2005; 16(3):97104

Artigo apresentado em 29/11/2011

Aprovado em 05/03/2011

Versão final apresentada em 30/03/2012 